\title{
JURISPRUDENCIA AMBIENTAL EN EL PAÍS VASCO (PRIMER SEMESTRE 2020)
}

IÑIGO LAZKANO BROTÓNS

Profesor colaborador

Universidad del País Vasco / Euskal Herriko Unibersitatea 
Sumario: 1. Evaluación ambiental y planeamiento urbanístico. 2. Carácter vinculante de los instrumentos de ordenación del territorio. 3. Contradicción entre la declaración de un bien cultural y la normativa de protección del medio natural. 4. Contrato de suministro y energías renovables. 5. Actividades clasificadas: a) Guardería canina en suelo no urbanizable; b) Disordancia entre normas técnicas de carácter general y ordenanzas locales. 6. Efectos en las licencias de obras de la normativa de suelo contaminados 7. La continua litigiosidad sobre el complejo medioambiental de Gipuzkoa

\section{EVALUACIÓN AMBIENTAL Y PLANEAMIENTO URBANÍSTICO}

En la STSJPV 2945/2019, de 17 de octubre (sala de lo contenciosoadministrativo, sección segunda, ponente: Rodrigo Landazabal), se resuelve el recurso planteado contra la modificación de las normas subsidiarias de Bakio, relativa a un determinado sector de suelo urbanizable residencial. La modificación se llevó a cabo como consecuencia de que el Tribunal Supremo había declarado la nulidad de las precedentes normas subsidiarias referentes a ese sector, por haber sido aprobadas sin el informe preceptivo exigido por la legislación de costas. El ayuntamiento emprendió entonces la elaboración de una nuevas normas subsidiarias para el sector (normas que debían ser aprobadas definitivamente por el órgano foral competente), para las que pidió (y obtuvo) el informe favorable de costas. Pero los recurrente alegaron que se trataba de un nuevo ejercicio pleno de la potestad de planeamiento municipal (no de un mero acto de ejecución de sentencia), por lo que debían ser cumplidas todas las exigencias que la normativa establece para su correcto ejercicio (programa de participación ciudadana, estudio de viabilidad económico-financiero, memoria de sostenibilidad económica, etc.), y, en particular, que al afectar a una zona ambientalmente sensible (la zona de servidumbre de protección de costas) debía haber sido objeto de una evaluación ambiental estratégica (al menos simplificada), como lo exige la normativa autonómica en conexión con la legislación básica estatal. EI TSJPV recuerda la jurisprudencia establecida por el Tribunal Supremo en torno a los efectos de la nulidad del planeamiento urbanístico: los efectos se producen ex tunc (lo que no permite la convalidación o conversión de trámites) y, en consecuencia, son aplicables los requisitos de la legislación vigente en el momento de dictarse el acuerdo de iniciación de las nuevas normas 
subsidiarias. Por ello se da la razón a los recurrentes, al estimar el TSJPV que al situarse parte del sector en zona de servidumbre de protección debió interesarse del órgano ambiental competente informe valorativo sobre la necesidad o no de someter las norma de planeamiento a evaluación ambiental.

También se ha pronunciado el TSJPV sobre la obligatoriedad de someter los planes especiales de ordenación urbana a evaluación ambiental. La STSJPV 3316/2019, de 12 de noviembre (sala de lo contencioso-administrativo, sección segunda, ponente: Ruiz Ruiz), señala que la previsión de la ley vasca del suelo respecto a que este tipo de planes no requieren de informe de evaluación conjunta (así es como la normativa vasca venía a denominar a la evaluación estratégica) de impacto ambiental ha de entenderse superada (incluso por derogación tácita de dicha norma). El desarrollo normativo de la legislación vasca medioambiental (operado previa deslegalización de algunos de sus contenidos) ha superado la exigencia de que los planes especiales han de ser evaluados cuando afecten al suelo no urbanizable, para considerar que su evaluación es obligatoria en tanto que pudieran tener efectos significativos en el medio ambiente, en la línea de lo establecido en la normativa europea y en la legislación básica estatal. Pese a ello, la sentencia flexibiliza de manera notoria las exigencias procedimentales de la evaluación, pues admite como válido un informe ambiental estratégico dictado con carácter previo a la aprobación definitiva del plan especial. La aprobación inicial del plan especial se produjo sin previa solicitud de inicio del procedimiento de evaluación y, por tanto, sin un documento ambiental estratégico a considerar. Sin embargo, este vicio de carácter formal carece por sí mismo de virtualidad invalidante para el TSJPV. Esta línea se mantiene en posteriores sentencias de este órgano judicial (STSJPV 3847/2019, de 16 de diciembre (sala de lo contenciosoadministrativo, sección segunda, ponente: Ruiz Ruiz). Es cierto que esta jurisprudencia es comprensible en la medida en la que los informes ambientales estratégicos que se dictaron en cada caso negaban los posibles efectos adversos significativos al medio ambiente y, por ende, concluían que no debía hacerse una evaluación ambiental estratégica ordinaria. Pero quedaría la duda de si, precisamente, a esa conclusión se habría llegado para no perjudicar la viabilidad del procedimiento de elaboración del plan llevado a 
cabo, puesto que si se hubiera dicho lo contrario resultaría evidente la nulidad de todo lo actuado (sobre todo por la falta de la fase de consultas al público interesado).

\section{CARÁCTER VINCULANTE DE LOS INSTRUMENTOS DE ORDENACIÓN DEL TERRITORIO}

En la STSJPV 2829/2019, de 17 de octubre (sala de lo contenciosoadministrativo, sección segunda, ponente: Ruiz Ruiz), se establece que la tipología incluida en la Ley de Ordenación del Territorio del País Vasco respecto de los grados de vinculación de la Directrices de Ordenación del Territorio en relación con los restantes instrumentos de planeamiento (diferenciando entre normas con carácter vinculante -directo o indirecto- y simples recomendaciones) es trasladable por la identidad de razón concurrente a la vinculación que producen los Planes Territoriales Parciales sobre el resto de planes (tanto de ordenación territorial sectorial como urbanísticos).

\section{CONTRADICCIÓN ENTRE LA DECLARACIÓN DE BIEN CULTURAL Y LA NORMATIVA DE PROTECCIÓN DEL MEDIO NATURAL}

La STSJPV 2829/2019, de 17 de octubre (sala de lo contenciosoadministrativo, sección segunda, ponente: Ruiz Ruiz), resuelve el recurso interpuesto por la Diputación Foral de Gipuzkoa contra la calificación como bien cultural, con la categoría de conjunto monumental, de la papelera del Araxes y sus infraestructuras hidráulicas, adoptada por el Gobierno Vasco. Son varias las cuestiones a resolver y pasan a exponerse de manera separada:

a) Para la Diputación Foral recurrente el decreto de calificación de bien de interés cultural tiene naturaleza de acto administrativo y, por lo tanto, ha de respetar las disposiciones de carácter reglamentario en materia ambiental, en este caso aprobadas por el propio Gobierno Vasco. EI TSJPV no acoge este motivo al entender que se trata en realidad de una disposición de carácter reglamentario, por establecer el régimen de protección que se otorga al conjunto, lo que incluye un régimen de usos y la imposición de determinaciones que se imponen al planeamiento urbanístico, sin perjuicio de que algunos elementos de la declaración (la delimitación de las infraestructuras hidráulicas y la descripción del elemento calificado) pudieran tener una naturaleza más 
próxima a la del acto administrativo. En este caso la declaración no supone la directa aplicación de un régimen de protección previamente establecido por otras disposiciones de carácter general, sino el establecimiento ex novo de un concreto régimen de protección que comporta limitaciones a los derechos y facultades de los ciudadanos.

b) Analiza el TSJPV la normativa de carácter medioambiental dictada específicamente para la zona, normativa de carácter previo a su calificación como bien cultural y dirigida a favorecer la continuidad de las aguas del río Araxes. Este río había sido declarado por el propio Gobierno Vasco zona de especial conservación (ES2120012), junto a otros trece ríos y estuarios de la región biogeográfica atlántica. Ello le dotaba de una normativa singular en materia de conectividad ecológica, de uso del agua, de actividades y actuaciones a realizar en ese espacio fluvial, de estado de conservación del corredor acuático, de eliminación, demolición y permeabilización de obstáculos, etc. De ahí que el motivo de la impugnación consistiera, fundamentalmente, en señalar las contradicciones entre el elenco de reglas existentes afectantes a ese espacio desde el punto de vista ambiental y las establecidas como consecuencia de su calificación como bien cultural. No se cuestiona en la sentencia la legalidad y justificación de la protección cultural acordada.

c) El núcleo central de lo debatido se refiere a la protección de la presa de Lizartza o Insalus (que se halla dentro del conjunto monumental calificado). La Diputación defiende que para garantizar la permeabilización y continuidad del caudal del río debe procederse a la eliminación de la presa, de manera coherente con lo exigido en la normativa medioambiental de la zona. Pero la declaración de la misma como parte del bien cultural lo impediría. El TSJPV valora los diferentes informes emitidos (en muchas ocasiones por los propios órganos del Gobierno Vasco: Viceconsejería de medio ambiente, URA-Agencia vasca del agua, etc.) en el procedimiento de declaración de la zona como bien cultural, que apuntaban en la misma dirección que el órgano foral recurrente, y llega a la conclusión de lo adecuado del motivo impugnatorio. Es imposible técnicamente un cauce alternativo (como preveía la regulación del bien cultural), por lo que las opciones son las que se señalaban en el informe de URA-Agencia vasca del agua: demolición completa, demolición parcial, 
construcción de paso naturalizado y escala de artesas o paso técnico. De haber sido posible el cauce alternativo, ésta hubiera sido la solución óptima y única, tanto por ser la mejor desde el punto de vista medioambiental, por ser el sistema más efectivo, como desde el cultural patrimonial, por ser el de menos afección para la presa, como bien catalogado. Pero eso no significa que el TSJPV avale la demolición de la presa para cumplir la normativa medioambienjtal en relación con la permeabilización, como pretendía el órgano foral recurrente. Se deberán valorar todas las alternativas viables (las ya señaladas) para dar satisfacción tanto a las exigencias de la normativa ambiental como a la de protección cultural.

\section{CONTRATO DE SUMINISTRO Y ENERGÍAS RENOVABLES}

La empresa pública de transportes urbanos de Vitoria (TUVISA) estableció dentro de los pliegos del contrato de suministro de energía eléctrica a los distintos puntos de los que es titular, unas cláusulas en las que exigía que la comercializadora que licitase al contrato debía estar calificada con la etiqueta $\mathrm{A}$ expedida por la Comisión Nacional de los Mercados y de la Competencia, y que éste organismo había además de acreditar que la energía que comercializase el adjudicatario fuera un $100 \%$ de origen renovable. Dos empresas eléctricas (Iberdrola Clientes y Endesa Energía) interpusieron recurso especial contra esos pliegos ante el Órgano Administrativo de Recursos Contractuales de la CAPV, órgano que dió la razón a las empresas recurrentes, al considerar que: a) ostentar la citada etiqueta $\mathrm{A}$ no implicaba necesariamente haber vendido exclusivamente energía de origen renovable, por lo que no existía concordancia entre el requisito solicitado y el alcance del documento que se pedía para acreditarlo; y b) era contrario a los principios de igualdad de trato y salvaguarda de la libre competencia no permitir el acceso a la licitación a las empresas que hubieran vendido un gran volumen de energía procedente de fuentes renovables, incluso aunque fuera muy superior al que representaba el valor estimado del contrato, si además hubieran vendido energía procedente de fuentes no renovables, fuera cual fuera este porcentaje y con independencia de la cantidad de energía de origen renovable que, en términos absolutos, hubieran suministrado. Contra esta resolución interpuso recurso TUVISA ante el TSJPV. 
En la STSJPV 2924/2019, de 16 de octubre (sala de lo contenciosoadministrativo, sección primera, ponente: Fernandez Fernandez), se va a estimar el recurso interpuesto por TUVISA. Para el órgano judicial una cosa es que la etiqueta $A$ no sea el medio idóneo para acreditar la solvencia técnica de las empresas que comercializan energía de origen únicamente renovable, por no atender a las magnitudes de sus operaciones sino únicamente al origen de la energía comercializada, y otra distinta es que tal falta de idoneidad tenga relevancia en la apreciación de las infracciones que motivaron los recursos en materia contractual estimados por la resolución recurrida. No se trata de la capacidad de las empresas del sector para comercializar energía de fuentes renovables, al margen de la correspondiente a otras fuentes, sino de su capacidad para suministrar energía que tenga únicamente aquel origen. Es un criterio de selección del poder adjudicador que atiende a los porcentajes del mix de comercialización y no a magnitudes absolutas por fuente de producción. La opción de TUVISA es tan libre como la de las empresas que intervienen en el mercado de la energía, y no tiene un carácter discriminatorio. En atención a los objetivos de política ambiental tampoco es indiferente al contratante la fuente (limpia o contaminante) de la energía suministrada, no en vano la demanda de ese producto, dependiendo de tal opción, propiciará un mayor o menor recurso a la producción y adquisición de energía de fuentes renovables para su suministro al consumidor o suministrado.

\section{ACTIVIDADES CLASIFICADAS.}

\section{A) Guardería canina en suelo no urbanizable}

La STSJPV 3500/2019, de 7 de noviembre (sala de lo contenciosoadministrativo, sección segunda, ponente: Rodrigo Landazabal), afirma que una actividad de guarda canina de menos de veinticinco perros se halla sometida, según la Ley General de Protección del Medio Ambiente del País Vasco, a comunicación previa de actividad. La propia norma establece una similitud entre explotaciones ganaderas, corrales domésticos y guarderías caninas, así como su implantación en suelo no urbanizable y suelo urbano industrial. Como ni por el número de perros, ni por la superficie, constituye la instalación un núcleo zoológico, la normativa establecida para estos últimos no resulta aplicable. $\mathrm{Y}$ aunque las normas subsidiarias de planeamiento de un 
municipio no contemplen específicamente el uso de guardería canina, continúa afirmando la sentencia, eso no significa que no sea posible desarrollar tal actividad. Y siendo así, es precisamente el suelo no urbanizable no protegido el que resulta más apto para el desarrollo de una actividad como la que se describe.

\section{B) Discordancia entre normas técnicas de carácter general y ordenanzas locales}

En la STSJPV 2124/2019, de 26 de septiembre (sala de lo contenciosoadministrativo, sección segunda, ponente: Ruiz Ruiz), se confirma en apelación la doctrina establecida en la sentencia de instancia de que en caso de contradicción entre las previsiones de las normas técnicas de carácter general de aplicación a las actividades molestas, insalubres, nocivas y peligrosas a establecer en suelo urbano residencial (reguladas en el Decreto 171/1985, de 11 de junio, dictado por el Gobierno Vasco) y lo establecido y efectivamente aplicado por los servicios municipales (la ordenanza municipal de medio ambiente), prima lo primero. Se trataba de una discordancia en relación a la ventilación de una discoteca. Mientras el Decreto 171/1985 exigía ventilación por chimeneas a una determinada cota, la ordenanza local consideraba suficiente la evacuación de aire enrarecido, lo que podría hacerse por un sistema de rejillas. Pese a que en la prueba pericial los intervinientes afirmasen que el citado Decreto 171/1985 estaba obsoleto y más que superado, lo cierto es que el mismo no ha sido derogado (la propia sentencia afirma, de manera rotunda, su vigencia y aplicabilidad), tratándose de una norma que pretende homogeneizar las normativa en materia de actividades clasificadas. $Y$ aunque se alegó, tanto en instancia como en apelación, que el ayuntamiento en actuaciones previas no habría exigido a otros sujetos, como a la recurrente, el cumplimiento de la exigencia de ventilación mediante la evacuación con sistema a dos metros encima del alero, tal alegación no puede prosperar por no ser asumible en derecho la consolidación del principio de igualdad dentro de la ilegalidad.

\section{EFECTOS EN LA LICENCIA DE OBRAS DE LA NORMATIVA DE SUELOS CONTAMINADOS}


La STSJPV 2769/2019, de 2 de octubre (sala de lo contencioso-administrativo, sección segunda, ponente: Ruiz Ruiz) resuelve el recurso de apelación planteado contra una sentencia de instancia que había anulado una licencia de obras y ordenado la retroacción de actuaciones para que se tuviera en cuenta por el ayuntamiento la resolución sobre calidad del suelo adoptada por el órgano administrativo competente en materia de medio ambiente. El asunto resulta de una cierta complejidad temporal. En el momento en el que el ayuntamiento otorga la licencia de obras para la habilitación de un albergue en suelo urbano, la parcela afectada no se encontraba incluida en el inventario de suelos contaminados aprobado por Decreto 165/2008 del Gobierno Vasco. Su inclusión en el citado inventario se produce con posterioridad. La licencia se impugna tanto por considerar que afecta a un suelo contaminado, como por otros motivos vinculados con los usos admitidos por el planeamiento general (esto último desestimado en la apelación, pero que la sentencia de instancia no entra ni a considerar). La sentencia del juzgado de lo contenciosoadministrativo anula la licencia otorgada y ordena la retroacción del procedimiento al momento en el que el ayuntamiento pueda considerar la resolución sobre calidad del suelo dictada por el órgano ambiental (que es posterior, lógicamente, a la inclusión de la parcela en el inventario de suelos contaminados y, por ende, a la fecha de otorgamiento de la licencia, pero anterior a la presentación del recurso contencioso contra esta última). En apelación el TSJPV estima el recurso interpuesto por una comunidad de propietarios en base al argumento de que la licencia otorgada sería nula de pleno derecho (y no meramente anulable), pues así lo establece la Ley 4/2015 para la prevención y corrección de la contaminación del suelo en relación a las licencias otorgadas sin pronuciamiento del órgano ambiental de la CAPV emitido en el marco de los procedimientos de declaración de calidad del suelo en los supuestos que éstos resulten exigibles. $Y$ el hecho de no hallarse incluida la parcela en el inventario no resulta trascendente a estos efectos, pues las obligaciones de esa ley derivan de que el suelo soporte o haya soportado una actividad o instalación potencialmente contaminante del suelo y no de la inclusión del mismo en el inventario, que tiene un carácter meramente informativo. $Y$ al tratarse de una parcela en la que se había desarrollado una actividad de artes gráficas (actividad recogida en el listado del anexo I de la Ley 
4/2015, de actividades e instalaciones potencialmente contaminantes del suelo), el informe del órgano ambiental resultaba inexcusable, so pena de nulidad.

\section{LA CONTINUA LITIGIOSIDAD SOBRE EL COMPLEJO MEDIOAMBIENTAL DE GIPUZKOA}

Continúan dictándose un amplio número de sentencias derivadas de la polémica instalación de la incineradora de Zubieta, de la que hemos venido dando cuenta en crónicas anteriores. En este período se han dictado la STSJPV 2572/2019, de 12 de septiembre (sala de lo contenciosoadministrativo, sección primera, ponente: Fernandez Fernandez) y la STSJPV 2595/2019, de 10 de septiembre (sala de lo contencioso-administrativo, sección primera, ponente: Murgoitio Estefanía), que estiman, entre otros aspectos, la adhesión a la apelación formulada por la Diputación Foral de Gipuzkoa y el Consorcio de Residuos de Gipuzkoa contra la sentencia de instancia y declaran la inadmisibilidad de los recursos contencioso-administrativos interpuestos por las Mancomunidades de Urola-Erdikoa y de Tolosaldea, por falta de legitimación de la entidades locales recurrentes. Para el TSJPV las citadas mancomunidades no sustentan su pretensión en el interés de la legalidad que dicen vulnerada por el anteproyecto de concesión administrativa para el diseño, construcción, financiación, operación y mantenimiento del Complejo Medioambiental de Gipuzkoa, Fase I. Se trata, a su entender, de la mera disidencia de criterio de unos miembros del Consorcio con el que, por vía de mayorías decisorias, ha dado legitimidad al acuerdo o actuación recurrida. En medida alguna se atisba en el caso enjuiciado una contraposición real de intereses que tomase como polos opuestos los de la Administración actuante en su conjunto y los específicos de los miembros disidentes (las citadas mancomunidades), pues no llega a singularizarse ningún alcance, afección o incidencia particular sobre el círculo de intereses de las recurrentes que derive del contenido del citado anteproyecto de concesión. El mismo argumento reproduce la STSJPV 2591/2019, de 10 de septiembre (sala de lo contenciosoadministrativo, sección primera, ponente: Murgoitio Estefanía), en relación al recurso que en su momento interpuso la Mancomunidad de Tolosaldea contra el acuerdo de aprobación del estudio de viabilidad de la concesión de la obra 
pública referida (Complejo Medioambiental de Gipuzkoa, Fase I) adoptado por la asamblea del Consorcio de Residuos de Gipuzkoa. 